\title{
EDITORIAL
}

\section{The definition of ARDS revisited: 20 years later}

\author{
Gordon R. Bernard ${ }^{1 *}$ and Antonio Artigas ${ }^{2,3}$
}

๑ 2016 Springer-Verlag Berlin Heidelberg and ESICM

More than 20 years ago we set out to create a definition for the acute respiratory distress syndrome (ARDS) in order to standardize clinical and research communication regarding ARDS. Ashbaugh and Petty had described most of the important clinical features of ARDS in 1967, which included hypoxemia, bilateral pulmonary infiltrates, decreased lung compliance, and microscopic evidence of diffuse alveolar damage, but they did not offer specific criteria of the type that could readily be used to define the disorder for clinical, epidemiology, and research purposes [1]. Under the auspices of the American Thoracic Society and the European Society of Intensive Care Medicine we co-chaired the American European Consensus Conference (AECC) on ARDS; this committee met formally in Miami on 15 May 1992 and concluded its work on 26 October 1992 in Barcelona. Membership on the committee included scientists from around the world [2-4]. The AECC recommended that patients be defined as having acute lung injury (ALI) if, in the context of a risk factor for ARDS, they had recent onset of hypoxemia $(\mathrm{P} / \mathrm{F} \leq 300 \mathrm{mmHg}$ regardless of use of PEEP) and a chest radiograph consistent with bilateral pulmonary edema. Those with a $\mathrm{P} / \mathrm{F}$ ratio $\leq 200 \mathrm{mmHg}$ were defined as ARDS. In both cases, patients were excluded if they had evidence of left atrial hypertension or a pulmonary artery wedge pressure of $>18 \mathrm{mmHg}$ that explained the pulmonary edema.

The AECC recognized that much remained to be done in this area and it was hoped that their work and future conferences would spur the development of an integrated international strategy for defining, quantifying, and studying ALI and ARDS. Indeed research was spurred given that the AECC publications have been cited more

*Correspondence: gordon.bernard@vanderbilt.edu

${ }^{1}$ Vanderbilt University School of Medicine, Nashville, TN, USA

Full author information is available at the end of the article than 7300 times and additional conferences have been conducted, e.g., the second AECC held in several cities in the USA and Europe from May 1993 until September 1996 [5] and the Berlin Conference held in Berlin in 2011. The second AECC did not change the definition whereas the Berlin conference resulted in recommendations that amended the AECC definition (Fig. 1).

The stated goals of the Berlin committee were to address perceived deficiencies in the definition of ARDS including: lack of explicit criteria for defining "acute," sensitivity of $\mathrm{PaO}_{2} / \mathrm{FiO}_{2}$ to different ventilator settings, poor reliability of the chest radiograph criterion, and difficulties distinguishing hydrostatic edema on frontal chest radiograph. The conceptual pathophysiologic model of ARDS was confirmed by the Berlin group [6] but correlations between pathologic findings and the clinical definition remain less than ideal [7].

The Berlin group clarified the AECC definition by defining "acute" to mean present for no more than 1 week. The addition of chest computed tomography as a tool for diagnosing pulmonary edema is a logical addition to the chest radiograph, though there are no validation studies that would indicate how such a tool is actually used for this purpose. The allowance for use of Swan-Ganz catheter measurements to exclude hydrostatic edema has been removed because this tool is less often used and because cardiac failure or volume overload can co-exist with ARDS. However, when the situation becomes confusing such as when there is no risk factor present, an echocardiogram is suggested. It is not clear how an echocardiogram is not similarly confounded in the situation where cardiac and non-cardiac pulmonary edema co-exist. Perhaps the greatest improvement in the definition comes from modification of the naming conventions. The concept of ALI being inclusive of the more severe ARDS has always been a bit confusing and was the subject of much debate at the AECC meetings. The change to mild, moderate, and severe ARDS for the same $\mathrm{PaO}_{2} / \mathrm{FiO}_{2}$ range of

\section{Springer}




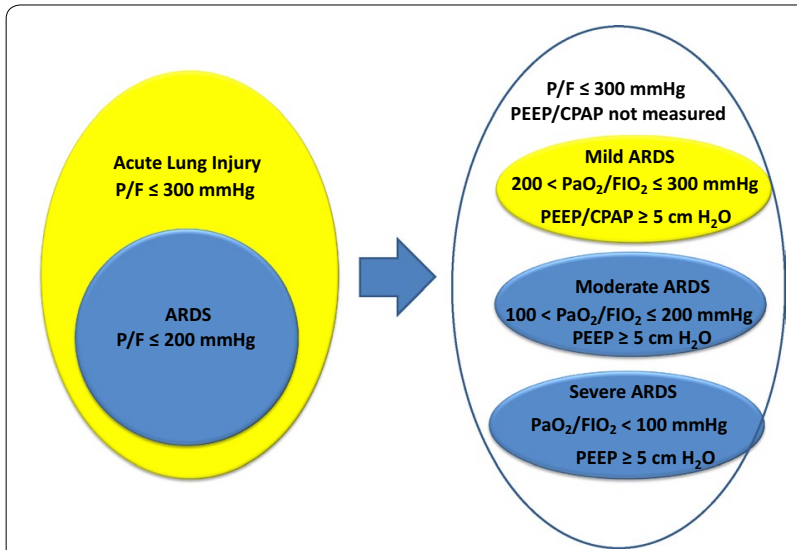

Fig. 1 Illustration of changes in ARDS definition moving from the AECC definition to the Berlin definition. For purposes of this figure all patients must have acute changes in chest radiograph consistent with pulmonary edema

0-300 mmHg greatly simplifies reporting. Unfortunately, the cutoffs for these categories were made by consensus rather than being data-driven, albeit ultimately the more severe category the worse the mortality.

One modification that is less clearly useful is the requirement for $5 \mathrm{cmH}_{2} \mathrm{O}$ of PEEP. The fact that PEEP can improve $\mathrm{P} / \mathrm{F}$ ratio seems irrelevant. If the lung is injured such that it meets the criteria of either definition, the fact that oxygenation can be made better with a clinical intervention does not negate the presence of injury. It seems similar to saying one does not have congestive heart failure if the condition responds to a small dose of diuretic. Indeed, the Berlin report indicates that approximately $12 \%$ of the 4188 patients in the databases used for validation of the definition did not have PEEP measured. One can only imagine how many people around the world with ARDS never have PEEP measured because they died before intubation or they were never mechanically ventilated perhaps foregoing end-of-life interventions. For clinical, research, or epidemiological purposes, do those patients NOT have ARDS? The Berlin group reports that the Berlin definition has better predictive validity for mortality than the AECC definition did, AUROC of 0.577 (95\% CI 0.561-0.593) vs. 0.536 (95\% CI 0.520-0.553). The AUROC difference of 0.041 was found to be statistically significant but it is hard to know that there is clinical meaning in such a small difference. The Berlin group considered new criteria but jettisoned these other requirements such as measurement of dead space or respiratory system compliance in the name of simplicity. The point was made that detailed evaluation of these measures for validity did not pan out such that a needlessly complex definition of ARDS was avoided. It seems that the PEEP requirement should have gone the same route.
For all of the improvements brought by the new ARDS definition, problems remain. Most frustrating is the lack of a biomarker (clinical laboratory test) that can be used to make the diagnosis. Even groups of biomarkers combining clinically available measures with the latest research-generated biomarkers, though promising, have not been compelling enough to be moved into clinical practice $[8,9]$. We still cannot readily measure permeability which is often considered the hallmark of ARDS. The role of hydrostatic pressure remains a major confounder and is not readily clarified by the use of echocardiograms or CT scans. Perhaps tools that hold potential for diagnosing increased lung water and/or permeability may take hold clinically [10-12]. Particularly important would be development of tools/criteria that may even be able to reliably predict development of ARDS [13].

\section{Author details \\ ${ }^{1}$ Vanderbilt University School of Medicine, Nashville, TN, USA. ${ }^{2}$ Critical \\ Care Department, CIBER Enfermedades Respiratorias, Corporacion Sanitaria Universitaria Parc Tauli, Parc Tauli 1, Sabadell, Spain. ${ }^{3}$ Autonomous University of Barcelona, Barcelona, Spain.}

\section{Compliance with ethical standards}

\section{Conflicts of interest}

On behalf of all authors, the corresponding author states that there is no conflict of interest.

Received: 11 February 2016 Accepted: 16 February 2016 Published online: 4 March 2016

\section{References}

1. Ashbaugh DG, Bigelow DB, Petty TL et al (1967) Acute respiratory distress in adults. Lancet 2:319-323

2. Bernard GR, Artigas A, Brigham KL, Carlet J, Falke K, Hudson L, Lamy M, LeGall JR, Morris A, Spragg R, The Consensus Committee (1994) The American-European Consensus Conference on ARDS: definitions, mechanisms, relevant outcomes, and clinical trial coordination. Am J Respir Crit Care Med 149:818-824

3. Bernard GR, Artigas A, Brigham KL, Carlet J, Falke K, Hudson L, Lamy M, LeGall JR, Morris A, Spragg R, The Consensus Committee (1994) Report of the American-European Consensus Conference on ARDS: definitions, mechanisms, relevant outcomes, and clinical trial coordination. Intensive Care Med 20:225-232

4. Bernard GR, Artigas A, Brigham KL, Carlet J, Falke K, Hudson L, Lamy M, LeGall JR, Morris A, Spragg R, The Consensus Committee (1994) Report on the American-European Consensus Conference on acute respiratory distress syndrome: definitions, mechanisms, relevant outcomes, and clinical trial coordination. J Crit Care 9(1):72-81

5. Artigas A, Bernard GR, Carlet J, Dreyfuss D, Gattinoni L, Hudson L, Lamy M, Marini JJ, Matthay MA, Pinsky MR, Spragg R, Suter PM (1998) The American-European Conference on ARDS, part 2: ventilatory, pharmacologic, supportive therapy, study design strategies, and issues related to recovery and remodeling (acute respiratory distress syndrome). Intensive Care Med 24(4):378-398

6. ARDS Definition Task Force, Ranieri VM, Rubenfeld GD et al (2012) Acute respiratory distress syndrome: the Berlin definition. JAMA 307:2526-2533

7. Thille AW, Esteban A, Fernandez-Segoviano P et al (2013) Comparison of the Berlin definition for acute distress syndrome with autopsy. Am J Respir Crit Care Med 187:761-767 
8. Calfee CS, Ware LB, Glidden DV et al (2011) Use of risk reclassification with multiple biomarkers improves mortality prediction in acute lung injury. Crit Care Med 39:711-717

9. Ware LB, Koyama T, Billheimer DD et al (2010) Prognostic and biochemical indices in patients with acute lung injury. Chest 137:288-296

10. Kor DJ, Warner DO, Carter RE et al (2015) Extravascular lung water and pulmonary vascular permeability index as a markers predictive of postoperative acute distress syndrome: a prospective cohort investigation. Crit Care Med 43:665-673
11. Le Tourneau JL, Pinney J, Phillips CR et al (2012) Extravascular lung water predicts progression to acute lung injury in patients with increased risk. Crit Care Med 40:847-854

12. Monnet $X$, Angel N, Osman D et al (2007) Assessing pulmonary permeability by transpulmonary thermodilution allows differentiation of hydrostatic pulmonary edema from ALI/ARDS. Intensive Care Med 33:448-453

13. Gajic O, Dabbagh O, Park PK et al (2010) Early identification of patients at risk of acute lung injury: evaluation of lung injury prediction score in a multicenter cohort study. Am J Respir Crit Care Med 183:462-470 